УДК 130.121.4

ББК 81.432.1-2я7

DOI: https://doi.org/10.17308/lic.2020.4/3074

\title{
ПАССИВНЫЕ И БЕЗЛИЧНЫЕ ГРАММАТИЧЕСКИЕ КОНСТРУКЦИИ В КОГНИТИВНО-ЛИНГВИСТИЧЕСКОМ АСПЕКТЕ
}

\author{
Е. В. Савицкая
}

Самарский государственный социально-педагогический университет

\section{PASSIVE AND IMPERSONAL GRAMMATICAL CONSTRUCTIONS IN THE MENTALINGUISTIC ASPECT}

\author{
E. V. Savitskaya \\ Samara State University of Social Sciences and Education
}

\begin{abstract}
Аннотация: в статье рассматривается зависимость между морфосинтаксическими свойствами языка и менталитетом народа. В частности, подвергается критике известный тезис, согласно которому личные конструкиии и частое употребление форм активного залога свидетельствуют об активности и инициативности носителей языка, тогда как регулярное использование безличных конструкций и пассивного залога - показатель пассивной жизненной позиџии и фатализма носителей языка. Доказывается, что такой корреляции не сущзествует. Отмечается, что на предыдущзих этапах развития языкознания грамматические факты объяснялись типологическими свойствами языков, но ныне появилась тенденция искать для них экстралингвистические (этнопсихологические и этнокультурные) причины. Показано: беда этих выводов и культурных параллелей состоит в том, что они имеют слабую доказательную базу. Их обоснование строится на том, что в английском языке существует много личных конструкций с подлежащим в номинативе, и это якобы свидетельствует, что англосаксы активны, ответственны, рациональны и способны контролировать свои ментальные состояния, в отличие от тех народов, в чьих языках есть много конструкиий без подлежащего в номинативе. Ошибка состоит в смешении номинатива и общего падежа и в убеждении, что личное подлежащее всегда выражает агенс. Автор опровергает этот тезис и доказывает существование корреляции между строем языка и стратегиями языкового мышления. Исследование проведено на материале английского и русского языков.

Ключевые слова: активный/пассивный залог, личная/безличная конструкция, тип языкового мышления, номинативный/общчий падеж, агенс/пащченс.
\end{abstract}

\begin{abstract}
: the article contains analysis of dependency between morphosyntactic properties of a language and mentality of an ethnos, as well as criticism of the notorious statement that personal constructions and frequent usage of active voice forms testify of activity and initiativity of native speakers of the language, whereas regular application of impersonal constructions and passive voice forms is an indicator of passive life position and fatalism of its native speakers. The author proves that such a correlation does not exist and mentions that at the previous stages of development of linguistics, grammatical facts were explained by the typological properties of languages, but now there is a tendency to look for extralinguistic (ethnopsychological and ethnocultural) reasons for them. The author shows: the trouble with these conclusions and cultural parallels is that they have a weak evidence base. Their justification is based on the fact that in English there are many personal constructions with a subject in the nominative, and this supposedly indicates that Anglo-Saxons are active, responsible, rational and able to control their mental states, unlike those nations in whose languages there are many constructions without the subject in the nominative. The error arises from mixing up the nominative case and the common case and in the belief that the personal subject always expresses the agent. The author refutes this belief and shows the correlation between the structure of the language and the strategies of verbal thinking. The research is based on the English and Russian language data.
\end{abstract}

Key words: Active/passive voice, personal/impersonal construction, type of verbal thinking, Nominative/Common case, agent/patient.

(C) Савицкая Е. В., 2020

(i) Контент доступен под лицензией Creative Commons Attribution 4.0 License.

The content is available under Creative Commons Attribution 4.0 License. 


\section{Введение}

На предшествующих этапах развития языкознания грамматические факты объяснялись прежде всего типологическими свойствами языков. Но начиная с 1990-х гг. под влиянием работ А. Вежбицкой ([1; 2] и др.) появилась тенденция искать экстралингвистические (этнопсихологические и этнокультурные) причины грамматических фактов. «Стало традицией противопоставлять англосаксонский языковой тип мышления русскому типу по признакам “активность, деятельность, контроль над ситуацией” и “пассивность, отсутствие контроля, неволитивность чувства”», - отметила С. М. Треблер [3, с. 147]. Можно сделать целую подборку цитат на эту тему, но они в основном повторяют вышеприведенную.

Делаются и еще дальше идущие выводы, носящие философско-этнологический характер. В качестве аргумента противопоставляются образы героев английской и русской литературы: волевой Чайльд-Гарольд употреблял личную конструкцию I want («Я хочу»), а безвольный Обломов - безличную конструкцию Мне хочется. Этнопсихологические выводы делаются на базе сравнения английского личного подлежащего и русской безличной конструкции. Корреляцию усматривают также между пассивной залоговой конструкцией и пассивной жизненной позицией.

Однако, как известно, конструкции с пассивной залоговой формой глагола широко применяются именно в английской речи. «Квантитативные исследования показали, что англичане прибегают к пассиву чаще, нежели носители других германских, а также славянских и романских языков», - отметил Е. В. Зарецкий [4, с. 2]. Английские пассивные конструкции высокочастотны потому, что служат функциональной заменой безличных морфосинтаксических конструкций, мало характерных для английской грамматики.

По Р. Г. Кодрингтону, «особо близко стоит к пассивному глаголу активный глагол, употребленный безлично» (цит. по: [5, с. 159]). Этого взгляда придерживался и Н. Мак-Коли: пассивные и безличные конструкции служат для выражения одной и той же семантики [6, p. 202]. А. А. Потебня и А. Н. Гвоздев тоже считали их синонимичными, а В. В. Виноградов даже считал безличные конструкции разрядом пассивных (по свидетельству Е. В. Зарецкого [4, с. 182]).

По М. М. Гухман, безличные и пассивные конструкции состоят в обратной пропорции: «В языках с развитым употреблением страдательного залога роль конструкций с дательно-винительным падежом лица сведена до минимума, а при отсутствии развитого употребления страдательного залога наблюдается продуктивность этой конструкции» [7, с. 156157]. Это подтверждается фактами: в английской речи предложения с пассивом частотнее безличных, а в русской речи - наоборот. Одни заменяют другие именно потому, что они эквивалентны.

Как же увязать факт высокой речевой частотности английских пассивных конструкций и низкой речевой частотности русских пассивных конструкций с утверждением об активной жизненной позиции англосаксов и пассивной позиции русских $([2 ; 8])$ ? Собственно говоря, никак. «Активные» англосаксы больше, чем русские, используют пассивный залог глагола, а «пассивные» русские больше, чем англосаксы, употребляют активный залог. Корреляция между жизненной позицией и залогом не прослеживается. Приведем подтверждения этого тезиса.

\section{Анализ языковых фактов}

Можно убедиться, что любой русской имперсональной конструкции с глаголом в активе соответствует английская конструкция с глаголом в пассиве:

Ветром распахнуло ставни - The shutters were pushed open by the wind (букв. «Ставни были распахнуты ветром»).

Тут-то его и прихватило - That's when he was suddenly taken ill (букв. «Вот когда он был внезапно охвачен недугом»).

У меня тяжело на душе - I am depressed (букв. «Я подавлен»).

Мне надлежит - I am obliged (букв. «Я обязан»).

Мне стыдно - I am ashamed (букв. «Я пристыжен»).

Мне боязно - I am scared (букв. «Я напуган») и т. п.

В учебниках по переводу русские безличные конструкции рекомендуется переводить на английский язык в первую очередь английскими конструкциями с пассивом. Это нормативные межъязыковые соответствия. Так где же здесь перевес «английской активности» над «русской пассивностью»? В этом плане английская и русская речь уравновешены; это подтверждается результатами подсчета, который был проведен Е. В. Зарецким на обширном материале русских и английских текстов. Зарецкий сделал вывод: «Никаких резких различий между английским и русским языком по количеству агентивных субъектных форм и пациентивных объектных форм не наблюдается» [4, с. 188].

Трогательные слова в защиту употребления пассивного залога в английской речи содержатся в интервью профессора Дж. Нанберга (Беркли): «Юлия Кристева однажды сказала, что изучение пассивного залога - это одна из тех вещей, которые делают нас человечнее. Это средство, позволяющее нам ощутить себя на месте тех, кто по воле истории сделался прямым объектом. Не те, кто действует, а те, на кого воздействуют. Вспомним существительные, которые мы образуем от пассивных форм глагола: униженные, 
оскорбленные, ограбленные, преследуемые, репрессированные. Пассивный залог особо уместен, когда людей вышвыривают из дома, лишают медпомощи, доводят до измождения. В цепочках пассивных форм слышится знакомая нота. В синтаксисе, которым пользовался Дж. Оруэлл, говоря о жертвах истории, беззащитные деревни бомбардируются, жители изгоняются в пустыню, домашний скот расстреливается из пулеметов, хижины предаются огню с помощью зажигательных пуль» $[9$, p. 3] (перевод наш. - E. C.).

Разумеется, англосаксам не чуждо милосердие; в их речи пассивный залог нередко выражает сочувствие к страждущим и обездоленным (passive от лат. pati «терпеть, страдать»). Эта гуманистическая позиция противостоит имперским по духу декларациям об английской грамматике как выразительнице «активного и гордого духа англосаксов - покорителей мира».

Беда вышеописанных ментально-языковых параллелей состоит в том, что они имеют слабую доказательную базу. Их обоснование строится на том, что в английском языке есть много личных конструкций с подлежащим в номинативе, и это якобы свидетельствует, что англосаксы активны, ответственны, рациональны и способны контролировать свои ментальные состояния, в отличие от народов, в чьих языках есть много конструкций без подлежащего в номинативе. Ошибка состоит в смешении номинативного и общего падежей и в убеждении, что личное подлежащее всегда выражает агенс. Но это не так. Английское существительное в позиции подлежащего имеет точно такую же морфологическую форму, что и существительное в позиции дополнения, а именно форму общего падежа.

Подлежащее в этой форме само по себе ничуть не «активнее» дополнения, имеющего ту же форму. Все дело в сказуемом: именно его семантикой и его формой, а не позицией подлежащего, определяется активность или пассивность актантов. В зависимости от сказуемого подлежащее может обозначать активного либо пассивного субъекта.

\section{Обсуждение результатов}

Констатируем ряд фактов, значимых в русле наших рассуждений:

- в английских предложениях падеж подлежащего - не номинативный;

- он выражает отнюдь не только агенс, но и все остальные семантические роли;

- в английской речи частотны конструкции с глаголом в пассиве, функционально эквивалентные безличным конструкциям;

- русские безличные конструкции всегда имеют корреляты - личные конструкции, что позволяет русским по желанию выражать мысли то лично, то безлично;

- английские конструкции с подлежащим в общем падеже равно передают как активность, так и пассивность, как своеволие, так и покорность судьбе;

- в любом народе есть как рационально, так и сумбурно мыслящие субъекты, и грамматика не помогает английским чудакам стать образцами здравомыслия.

На этом фоне тезис об особо активном и особо рациональном характере английской грамматики не выдерживает критики. Фиксированный порядок слов, почему-то принимаемый за признак и результат стройной логичности мышления, на самом деле возник по причине, не имеющей отношения к национальному характеру, - вследствие слабого произношения английских безударных гласных, которое в среднеанглийский период привело к редукции и последовавщему отпадению флексий у английского существительного [10].

У ограниченной вариативности английского порядка слов нет достоинств. Чтобы преодолеть эту ограниченность, англосаксам приходится прибегать к ухищрениям (логическому ударению, выделительным конструкциям и др.).

«При пациентивной ориентации (как в русском языке)... акцент делается на “бессилии” и пациентивности (“я ничего не могу делать, разные вещи случаются со мной”)», - такова точка зрения А. Вежбицкой [2, с. 64]. «Именно пациентивно ориентированная модель для русской языковой и ментальной картин мира является культуроспецифичной», - вторит ей Е. В. Устинова [11, с. 11]. Однако, по нашим наблюдениям, этот вывод безоснователен. Ведь именно для английского, а не для русского языка характерны конструкции с глаголом в пассивном залоге, в которых подлежащее выражает именно пациентивность, а не агентивность.

Поистине гипнотическое влияние на некоторых исследователей оказывает английское подлежащее в форме общего падежа, присущее даже пассивным конструкциям; в нем лингвистам чудится активное начало - агенс - несмотря на пассивную форму глагола. Но в предложении John was killed with a lightning (букв. «Джон был убит молнией») актант John (пациенс) ничуть не «агентивнее», чем актант Иван (пациенс) в русском предложении Ивана убило молнией. Ведь, как упоминалось, пассивная и безличная конструкции равнозначны и функционально эквивалентны. Джон и Иван - в равной мере жертвы обстоятельств (пациенсы). «Агентивность» Джона, убитого молнией, - это иллюзия, вызванная пресловутой формой общего падежа, почему-то считающегося номинативным. Приписывание мертвецу роли агенса вызывает легкое содрогание, наводя на мысль о зомби. 
По-русски тоже можно сказать Иван был убит молнией, и никому не придет в голову утверждать, что здесь Иван - агенс, хотя его имя стоит в номинативном падеже. Почему же Джон - агенс? Потому что он англосакс? Но это уже чистой воды предвзятое мнение, содержащее в себе шовинистический этностереотип и не имеющее отношения к подлинно научному лингвистическому анализу.

Порой складывается впечатление: ряд лингвистов исходят из априорного мнения, что носители лингвокультуры намеренно создают себе такую систему грамматики, которая выражает базовые черты их менталитета. Получается, что англосаксы нарочно «сделали» себе порядок слов «подлежащее - сказуемое - дополнение», чтобы выразить свою инициативность и активность.

Но грамматика в значительной мере развивается по своим законам, а не по воле носителей языка. В частности, как отмечалось, фиксированный порядок слов возник в английском предложении не потому, что англосаксы мыслят строго и логично, а потому, что редукция безударных привела к отпадению флексий у существительного, и варьирование порядка слов резко ограничилось.

Странно было бы полагать, что англосаксы (и другие народы, в чьих языках имя существительное имеет скудную падежную систему либо не имеет ее вовсе) специально редуцировали свои безударные гласные, чтобы сделать неизменным свой порядок слов и таким способом выразить стройность и логичность своего мышления. На самом деле фонетические изменения протекают бессознательно.

К тому же, по нашим наблюдениям, ригидность синтаксиса не способствует стройности и логичности мышления. Скорее наоборот - им способствует гибкость синаксической структуры, проявляющаяся в поливариантности порядка слов.

Обобщая сказанное выше, отметим, что многие популярные ментально-языковые параллели при тщательном рассмотрении выглядят в той или иной мере натянуто, умозрительно и предвзято, демонстрируя идейно-пропагандистский уклон там, где требуется объективный научный анализ. Что касается наших (приведенных выше) соображений по данному вопросу, они не ориентированы ни на критику, ни на апологию той или иной лингвокультуры. Напротив, мы привели аргументы против идеологизации науки. Мы постарались, в соответствии с известным принципом «Сущностей не следует умножать сверх необходимости» [12], оставаться в русле собственно лингвистической аргументации. В частности, опора на принципы типологии языков дает возможность выдвинуть гораздо более убедительное объяснение межъязыковым различиям в порядке слов, нежели апелляция к внеязыковому фактору - разнице в этническом менталитете народов.

Грамматические свойства (порядок слов, соотношение личных и безличных конструкций) обусловлены прежде всего строем (аналитическим/синтетическим) и типом языка (флективным, корнеизолирующим и др.). Например, вариативность порядка слов определяется синтетизмом и флективностью языка. На флективных языках говорят народы, проживающие в разных уголках Земли и значительно различающиеся менталитетом, - ирландцы, литовцы, русские, народы Западной Африки и др. Их языки имеют поливариантный порядок слов. Так определяется ли он менталитетом народа или все же типом языка?

\section{Заключение}

Исследования в области универсальной грамматики ([13-17] и др.) позволили выявить единую инвариантную систему грамматических закономерностей, по отношению к которой грамматические системы отдельных языков выступают как варианты. На наш взгляд, специфика языкового мышления каждого народа состоит не столько в том, что в грамматику этноязыка заложен менталитет этого народа, сколько в том, какими стратегиями пользуется языковое мышление данного народа для выражения универсальных грамматических значений (таких как тема и рема, семантические роли, гендер, субъект-объектные отношения, модальные и темпоральные значения и др.), исходя из возможностей грамматической системы родного языка.

\section{ЛИТЕРАТУРА}

1. Вежбиикая А. Семантика грамматики. М. : Изд-во Российской академии наук, 1992. 32 с.

2. Вежбиикая А. Русский язык // Язык. Культура. Познание. М. : Русские словари, 1996. С. 33-88.

3. Треблер С. М. Судьба русского литературного языка в Евразийском контексте // Труды Евразийского форума «Гумилевские чтения» : в 2 т. Астана, 2004. Т. 2. C. $135-152$.

4. Зареикий Е. В. О русском фатализме в грамматике // Культура : научно-культурологический журнал. 2007. № 12. URL: http://www.relga.ru/Environ/WebObjects/ tguww.woa/wa/Main?textid=2 030\&levell=mvell=main\& level $2=$ artides

5. Тромбетти А. О теории пассивного характера глагола // Эргативная конструкция предложения : сб. науч. трудов. М. : Изд-во иностранной литературы, 1950. C. $152-166$.

6. McCawley N. From OE/ME Impersonal to Personal Constructions : What Is a Subjectless S? // Papers from the Parasession on Diachronic Syntax. April 22.1976 / ed. by S. Steever. Chicago Linguistic Society, 1976. Pp. 192-205. 
7. Гухман М. М. Конструкции с дательно-винительным лица в индоевропейских языках // Известия АН СССР. Отделение литературы и языка. 1945. № 4. C. $148-157$.

8. Чернавская Ю. В. Народная культура и национальные традиции. Минск : Беларусь, 2000. 421 с.

9. Nunberg G. Passionate about the Passive Voice // NPR Program Stream. Transcript. 2019. URL: https://www. npr.org/ templates/sto ry.php?storyId $=103709904$

10. Расторгуева T. А. История английского языка. M. : ACT, 2003. 348 c.

11. Устинова E. В. Функционально-семантическое поле агентивности/неагентивности в современном русском литературном языке XX - начала XXI вв. : автореф. дис. ... канд. филол. наук. Ростов н/Д., 2007. 26 с.

12. Оккам У. Избранное. М. : Едиториал УРСС, 2002. $272 \mathrm{c}$.

13. Арно А., Лансло К. Всеобщая рациональная грамматика. Л. : Изд-во Ленинград. гос. ун-та, 1991. 126 с.

14. Мельчук И. А. Опыт теории лингвистических моделей «Смысл ↔ текст». М. : Школа «Языки русской культуры», 1999. 346 с.

15. Филлмор Ч. Дело о падеже // Зарубежная лингвистика. М. : Прогресс, 1999. Вып. 3. С. 127-258.

16. Шаумян C. K. Аппликативная грамматика как семантическая теория естественных языков. Ленинград : Наука, 2013. 204 с.

17. Хомский Н. Картезианская лингвистика. М. : Эдиториал URSS, 2018. 232 c.

\section{REFERENCES}

1. Wierzbicka A. Semantika grammatiki [Semantics of grammar]. Moscow: Izdatelstvo Rossijskoj akademii nauk, 1992. $32 \mathrm{p}$.

2. Wierzbicka A. Russkij Yazyk [The Russian language]. In: Yazyk. Kultura. Poznaniye. Moscow: Russkiye slovary, 1996. Pp. 33-38.

3. Trebler S. M. Sudba russkogo literaturnogo yazyka v Yevrazijskom kontekste [The fate of standard Russian in the Eurasian context]. In: Trudy Yevrazijskogo foruma "Gumilevskiye chteniya”. V 2-kh tt. Tom 2. Astana, 2004. Pp. 135-152.

4. Zaretsky Ye. V. O russkom fatalisme v grammatike [On Russian fatalism in grammar]. In: Kultura. Nauchno-kulturologichesky zhurnal. No. 12. 2007. Available at: http://www.relga.ru/Environ/WebObjects/tguww.woa/wa/ Main?textid $=2030 \& l e v$ el $=$ mvel $1=$ main\&level $2=$ artides

Самарский государственный сочиально-педагогический университет

Савицкая Е. В., дочент кафедры английской филологии и межкультурной коммуникации

E-mail: lampasha90@mail.ru

Поступила в редакичюю 10 июля 2020 г.

Принята к публикаџии 25 сентября 2020 г.
5. Trombetti A. O teorii passivnogo kharaktera glagola [On the theory of the passive character of verb]. In: Ergativnaya konstruktsiya predlozhenija: Sbornik nauchnykh trudov. Moscow: Izdatelstvo inistrannoy literatury, 1950. Pp. 152-166.

6. McCawley N. From OE/ME Impersonal to Personal Constructions: What Is a Subjectless S?. In: Papers from the Parasession on Diachronic Syntax. April 22.1976 / ed. by S. Steever. Chicago Linguistic Society, 1976. Pp. 192-205.

7. Gukhman M. M. Konstruktsii s datelno-vinitelnym litsa $\mathrm{v}$ indoyevropeiskikh yazykakh [Constructions with dative-accusative of person in Indo-European languages]. In: Izvestiya AN SSSR. Otdelenije literatury i yazyka. 1945. No. 4. Pp. 148-157.

8. Chernavskaya Yu.V. Narodnaya kultura i natsionalnye traditsii [Folk culture and national traditions]. Minsk: Belarus, 2000. $421 \mathrm{p}$.

9. Nunberg G. Passionate about the Passive Voice. In: NPR Program Stream. Transcript. 2019. Available at: https:// www.npr.org/ templates/sto ry.php?storyId $=103709904$

10. Rastorguyeva T. A. Istoriya angliyskogo yazyka [The history of the English language]. Moscow: AST, 2003. $348 \mathrm{p}$.

11. Ustinova Ye. V. Funktsionalno-semanticheskoye pole agentivnosti/neagentivnosti v sovremennom russkom literaturnom yazyke XX - nachala XXI vv. [Functional semantic field of agentivity / non-agentivity in modern Russian standard language of XX - early XXI Century]. PhD Dissertation Abstract. Rostov-n/D., 2007. 26 p.

12. Okkam W. Izbrannoye [Selected Papers]. Moscow: Editorial URSS, 2002. 272 p.

13. Arnauld A., Lancelot K. Vseobshchaya universalnaya grammatika [Universal grammar]. Leningrad: izdatelstvo Leningradskogo gos. universiteta, 1991. 126 p.

14. Melchuk I. A. Opyt teorii lingvisticheskikh modeley "Smysl $\leftrightarrow$ Tekst" [An experience of creating linguistic models "Sense $\leftrightarrow$ text"]. Moscow: Shkola "Yazyki russkoy kultury", 1999. 346 p.

15. Fillmore Ch. Delo o padezhe [The case for case]. In: Zarubezhnaya lingvistika. Vyp. 3. Moscow: Progress, 1999. Pp. 127-258.

16. Shaumyan S. K. Applikativnaya grammatika kak semanticheskaya teoriya yestestvennykh yazykov [Applicative grammar as a semantic theory of natural languages]. Leningrad: Nauka, 2013. 204 p.

17. Chomsky N. Kartezianskaya lingvistika [Cartesian Linguistics]. Moscow: Editorial URSS, 2018. 232 p.

Samara State University of Social Sciences and Education

Savitskaya E. V., Associate Professor of the English Philology and Cross-cultural Communication Department E-mail: lampasha90@mail.ru

Received: 10 July 2020

Accepted: 25 September 2020 


\section{Для цитирования:}

Савицкая E. В. Пассивные и безличные грамматические конструкции в когнитивно-лингвистическом аспекте // Вестник Воронежского государственного университета. Серия: Лингвистика и межкультурная коммуникация. 2020. № 4. C. 13-18. DOI: https://doi. org/10.17308/lic.2020.4/3074

\section{For citation:}

Savitskaya E. V. Passive and impersonal grammatical constructions in the mentalinguistic aspect. Proceedings Voronezh State University. Series: Linguistics and Intercultural Communication. 2020. No. 4. Pp. 13-18. DOI: https://doi.org/10.17308/lic.2020.4/3074 